\title{
On the structure and normal modes of hydrogenated Ti-fullerene compounds
}

\author{
Alfredo Tlahuice-Flores • Sergio Mejía-Rosales • \\ Donald H. Galván
}

Received: 14 March 2012/Accepted: 13 July 2012/Published online: 25 July 2012

(C) Springer Science+Business Media B.V. 2012

\begin{abstract}
When titanium covers a $\mathrm{C}_{60}$ core, the metal atoms may suppress the fullerene's capacity of storing hydrogen, depending on the number of $\mathrm{Ti}$ atoms covering the $\mathrm{C}_{60}$ framework, the Ti-C binding energy, and diffusion barriers. In this article, we study the structural and vibrational properties of the $\mathrm{C}_{60} \mathrm{TiH}_{n}$ ( $n=2,4,6$, and 8 ) and $\mathrm{C}_{60} \mathrm{Ti}_{6} \mathrm{H}_{48}$ compounds. The IR spectra of $\mathrm{C}_{60} \mathrm{TiH}_{n}$ compounds have a maximum attributable to the $\mathrm{Ti}-\mathrm{H}$ stretching mode, which shifts to lower values in the structures with $n=4,8$, while their Raman spectra show two peaks corresponding to
\end{abstract}

This article is part of the topical collection on nanomaterials in energy, health and environment

A. Tlahuice-Flores $(\bowtie)$

Instituto de Física, Universidad Nacional Autónoma de México, Apartado Postal 20-364, 01000 Mexico, DF, Mexico

e-mail: tlahuicef@yahoo.com

S. Mejía-Rosales

CICFIM-Facultad de Ciencias Físico Matemáticas, and Centro de Innovación, Investigación y Desarrollo en Ingeniería y Tecnología, Universidad Autónoma de Nuevo León, 66450 San Nicolás de los Garza, NL, Mexico

e-mail: sergio.mejiars@uanl.edu.mx

\section{H. Galván}

Centro de Nanociencias y Nanotecnologia-Universidad Nacional Autónoma de México, Apartado Postal 2681, Ensenada, BC, Mexico

e-mail: donald@cnyn.unam.mx the stretching modes of $\mathrm{H}_{2}$ molecules at apical and azimuthal positions. On the other hand, the IR spectrum of $\mathrm{C}_{60} \mathrm{Ti}_{6} \mathrm{H}_{48}$ shows an intense peak due to the $\mathrm{Ti}-\mathrm{H}$ in-phase stretching mode, while its Raman spectrum has a maximum attributed to the pentagonal pinch of the $\mathrm{C}_{60}$ core. Finally, we have found that the presence of one apical $\mathrm{H}_{2}$ molecule enhances the pentagonal pinch mode, becoming the maximum in the Raman spectrum.

Keywords Raman · Hydrogen storage . Coated fullerene $\cdot$ Transition metals Infrared . Atomic clusters

\section{Introduction}

The number of studies of new nanostructures (Zhao et al. 2005; Iñiguez et al. 2007; Yildirim et al. 2005; Bauschlicher et al. 2002; Zope et al. 2009; Zhang et al. 2000; Yoon et al. 2008; Yang et al. 2009; Lee et al. 2008; Durgun et al. 2008; Koh et al. 2011, Kiran et al. 2006) able to absorb $\mathrm{H}_{2}$ in at least $9 \mathrm{wt} \%$ have increased in the last years, following the goal proposed by the US Department of Energy of developing a system with this net gravimetric capacity for hydrogen storage. Among the different materials under consideration, systems composed by $\mathrm{C}_{60}$ compounds coated with transition metals are between the most promising ones. Nevertheless, most of the reports on the properties of these nanomaterials have concentrated their attention to the 
calculation of adsorption energies, although a few valuable exceptions exist; the need of a vibrational characterization of the hydrogenated $\mathrm{C}_{60} \mathrm{TiH}_{n}$ compounds, by example, has been remarked by Iñiguez et al., and their study on infrared spectra give value to this kind of calculations (Iñiguez et al. 2007).

In comparison with other transition metals, Titanium has a small atomic radius (it has a metallic radius of $1.45 \AA$ ), which potentiates its use as a material in hydrogen storage devices. However, Ti atoms have a known tendency to form clusters when attached to a $\mathrm{C}_{60}$ core, which is a factor of inhibition of the hydrogen adsorption (Sun et al. 2005). Thus, a main issue is to estimate how many Ti atoms can be attached to the fullerenic cage without being close to each other enough to allow the formation of clusters. In the case of Pt and Ir atoms, there exist previous reports of the synthesis of hexa-coordinated compounds, and it has been found that once that six Pt atoms are bound to the fullerenic cage, it is not possible the addition of more atoms (Fajan et al. 1991, 1992; Bach et al. 1991).

Recently, a study of single transition-metal atoms laying on graphene and on a $(8,0)$ single-wall carbon nanotube (SWCNT) has made clear that the clustering of the transition metal atoms depends on factors such as low metal binding energy and low diffusion barriers (Valencia et al. 2010). While these factors determine the clustering of $\mathrm{Ti}$ atoms specifically on graphene and SWCNT with a large diameter (Krasnov et al. 2007), it is likely that the same will occur on $\mathrm{C}_{60}$, but in this case the small diameter and large curvature of $\mathrm{C}_{60}$ would difficult the clustering and would make the fullerene a suitable candidate as substrate for transition metals.

In this article we report the all-electron calculation of the IR and Raman spectra of the hexa-coordinated $\mathrm{C}_{60} \mathrm{TiH}_{n}$ compounds and the more hydrogenated $\mathrm{C}_{60} \mathrm{Ti}_{6} \mathrm{H}_{48}$ compound (point group $T_{h}$ ), and demonstrate the feasibility of their synthesis in accordance with its calculated spectra. In order to be able to perform these calculations despite their computational cost (mostly because of the high use of memory), the symmetry of each compound has been exploited to reduce computing time and make more feasible these calculations.

\section{Theoretical methods and computational details}

All the calculations were performed within the density functional theory (DFT) framework (Hohenberg and
Kohn 1964). It is known that DFT is a theoretical tool of great reliability in the study of fullerene-like structures, since it reproduces quantitatively some of their main properties measured by experiments, and is able to predict some others when there are no preliminary experimental measurements. Concerning to the prediction of vibration frequencies, DFT has proven to be, in general terms, a reliable tool; even when the predicted values may present deviations from those measured in experiments, usually these deviations are systematic, in such a way that a scaling factor is enough to adjust the predicted values with the experimental results.

The all-electron DFT calculations in this study were carried out by using the Gaussian 03 package (Frisch et al. 2003), with the B3LYP exchange-correlation functional, a 6-31G(d) basis set, and a tight convergence criterion of the auto-consistent cycle (SCF). The choice of a base that includes polarization functions is based on reports showing that these functions have influence on the prediction of the Raman intensities (Halls and Bernhard 1999).

The binding energy $\left(E_{\mathrm{b}}\right)$ was estimated using the following expression:

$E_{\mathrm{b}}=\left[\left(E\left(\mathrm{C}_{60}\right)+E\left(\mathrm{Ti}_{n}\right)\right)-E\left(\mathrm{Ti}_{n} / \mathrm{C}_{60}\right)\right] / n$,

where $E\left(\mathrm{C}_{60}\right)$ is the total energy of the pure $\mathrm{C}_{60}, E\left(\mathrm{Ti}_{n}\right)$ is the $\mathrm{Ti}_{n}$ cluster's total energy, and $E\left(\mathrm{Ti}_{n} / \mathrm{C}_{60}\right)$ is the total energy of the $\mathrm{Ti}_{n}$ cluster adsorbed on the $\mathrm{C}_{60}$.

Previous to the study of $\mathrm{C}_{60} \mathrm{TiH}_{n}$ compounds, we calculated the binding energy of a Ti atom on the $\mathrm{C}_{60}$, testing the $(6,6),(5,6)$, pentagonal and hexagonal sites. From the results of these calculations it can be concluded that the best site to bind the Ti atom is on the $(6,6)$ bond $\left(E_{\mathrm{b}}\right.$ of $\left.2.38 \mathrm{eV}\right)$, followed by the $(5,6)$ site $(1.80 \mathrm{eV})$, and the hexagonal site $(1.48 \mathrm{eV})$. A later estimate of the binding energy $\left(E_{\mathrm{b}}\right)$ for the $\mathrm{Ti}$ atom bound to $(6,6)$ bond was calculated taking into account the basis set superposition error (BSSE) that arises from the use of an incomplete basis set to represent the interacting species (fragments). The corrected $E_{\mathrm{b}}$ was $2.45 \mathrm{eV}$. We discarded the case of the bond with a pentagonal ring, since the calculation predicts one imaginary frequency. These results disagree with those obtained by Yildirim et al. (2005) that using the supercell and a pseudopotential approximation, reported that the Ti adsorbed on the hexagonal ring is the most stable one. Nevertheless, our results are consistent with the known capacity of 
transition metals to bind to the $(6,6)$ bond (Mathur et al. 1998; Shin et al. 2006).

A set of isomers for the $\mathrm{C}_{60} \mathrm{TiH}_{n}$ compounds (point group $C_{2 v}$ ) and the $\mathrm{C}_{60} \mathrm{Ti}_{6} \mathrm{H}_{48}$ compound (point group $T_{h}$ ) were calculated, and the isomers with imaginary frequencies were let out of the study. The $\mathrm{C}_{60} \mathrm{TiH}_{2}$ molecule was prepared with two $\mathrm{H}$ atoms bound to the $\mathrm{Ti}$ atom, forming a cyclopropane-like bond with two carbon atoms of the $\mathrm{C}_{60}$ core (Fig. 1a). The $\mathrm{C}_{60} \mathrm{TiH}_{4}$ molecule has, in addition, one more apical $\mathrm{H}_{2}$ molecule (Fig. 1b). The $\mathrm{C}_{60} \mathrm{TiH}_{6}$ molecule is obtained when two azimuthal $\mathrm{H}_{2}$ are bound to the original $\mathrm{C}_{60} \mathrm{TiH}_{2}$ molecule (Fig. 1c). Finally, the $\mathrm{C}_{60} \mathrm{TiH}_{8}$, is a $\mathrm{C}_{60} \mathrm{TiH}_{6}$ molecule with an additional apical $\mathrm{H}_{2}$ molecule (Fig. 1d). The optimized $\mathrm{C}_{60} \mathrm{Ti}_{6} \mathrm{H}_{48}$ compound has six $\mathrm{TiH}_{8}$ units in an octahedral array (Fig. 1e).

\section{Results and discussion}

\section{Bond lengths}

The different characteristic bond lengths on each system are summarized in Table 1 . We can note that the $\mathrm{H}-\mathrm{H}$ bonds may have two different lengths, depending on the relative position of the $\mathrm{H}_{2}$ molecule with respect to the whole structure, the apical $\mathrm{H}_{2}$ molecules being larger than the azimuthal ones.

On the other hand, the $\mathrm{Ti}-\mathrm{H}$ bond, as in the original $\mathrm{C}_{60} \mathrm{TiH}_{2}$, is large when apical $\mathrm{H}_{2}$ molecules are present, and short when azimuthal $\mathrm{H}_{2}$ molecules are added. The characteristic bond lengths of the $\mathrm{C}_{60} \mathrm{TiH}_{n}$ compounds are compared in Fig. 2, and the specific
Table 1 Bond length values, in $\AA$, for all the calculated compounds

\begin{tabular}{lll}
\hline Compounds & Bond & Bond length $(\AA)$ \\
\hline $\mathrm{C}_{60}$ & $\mathrm{C}-\mathrm{C}$ & 1.395 \\
& $\mathrm{C}=\mathrm{C}$ & 1.453 \\
$\mathrm{C}_{60} \mathrm{TiH}_{2}$ & $\mathrm{Ti}-\mathrm{H}$ & 1.723 \\
$\mathrm{C}_{60} \mathrm{TiH}_{4}$ & $\mathrm{H}_{2}$, apical & 0.782 \\
& $\mathrm{Ti}-\mathrm{H}$ & 1.733 \\
$\mathrm{C}_{60} \mathrm{TiH}_{6}$ & $\mathrm{H}_{2}$, azimutal & 0.761 \\
& $\mathrm{Ti}-\mathrm{H}$ & 1.72 \\
$\mathrm{C}_{60} \mathrm{TiH}_{8}$ & $\mathrm{H}_{2}$, apical & 0.793 \\
& $\mathrm{H}_{2}$, azimutal & 0.764 \\
& $\mathrm{Ti}-\mathrm{H}$ & 1.725 \\
$\mathrm{C}_{60} \mathrm{Ti}_{6} \mathrm{H}_{48}$ & $\mathrm{H}_{2}$, apical & 0.792 \\
& $\mathrm{H}_{2}$, azimutal & 0.765 \\
& $\mathrm{Ti}-\mathrm{H}$ & 1.736 \\
\hline
\end{tabular}

case of $\mathrm{C}_{60} \mathrm{TiH}_{8}$ is compared against the bond lengths for the $\mathrm{C}_{60} \mathrm{Ti}_{6} \mathrm{H}_{48}$ in Fig. 3; here, we can note that the existence of six $\mathrm{Ti}$ atoms bound to the $\mathrm{C}_{60}$ core produces a deformation of the near $\mathrm{C}-\mathrm{C}$ bonds.

IR and Raman spectra

The obtained frequencies and their irreducible representations use Mulliken symbols. In this notation, A and $\mathrm{B}$ represent 1 dimension or 1 degeneracy, $\mathrm{E}$ represents twofold degeneracy and $\mathrm{T}$ represents threefold degeneracy.

In general, the IR and Raman spectra (Figs. 4 and 5, respectively) for the calculated $\mathrm{C}_{60} \mathrm{TiH}_{n}$ compounds

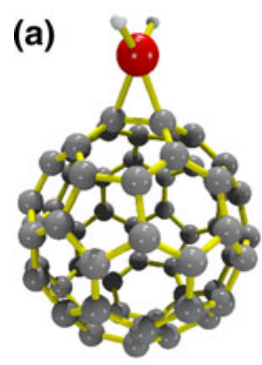

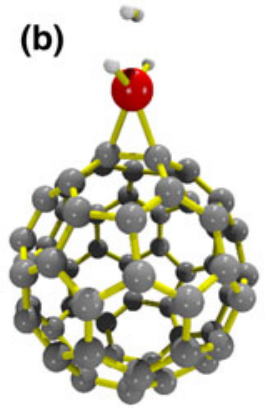

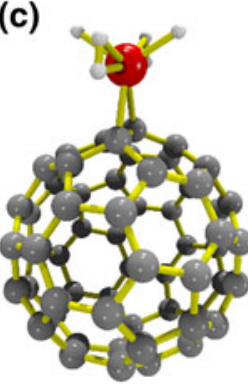

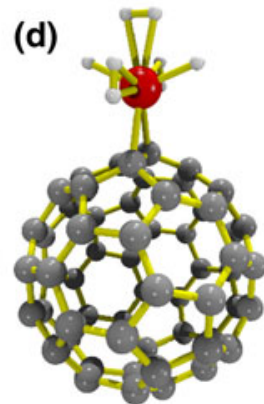

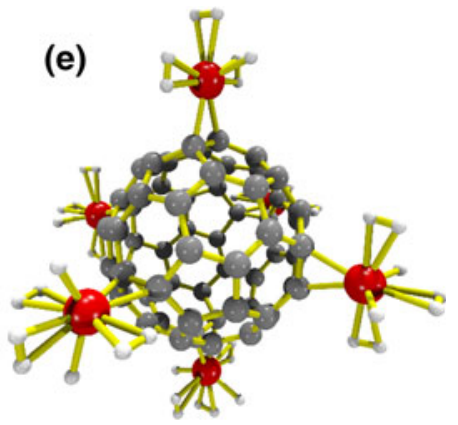

Fig. 1 Ball and stick models of the optimized $\mathrm{C}_{60} \mathrm{TiH}_{n}$ compounds with $C_{2 v}$ symmetry, and the $\mathrm{C}_{60} \mathrm{Ti}_{6} \mathrm{H}_{48}$ compound with $T_{h}$ symmetry. The atoms of $\mathrm{Ti}$ (red), $\mathrm{C}$ (gray), and $\mathrm{H}$ (white) are depicted. a $\mathrm{C}_{60} \mathrm{TiH}_{2}, \mathbf{b} \mathrm{C}_{60} \mathrm{TiH}_{4}$ with one apical $\mathrm{H}_{2}$ molecule, c $\mathrm{C}_{60} \mathrm{TiH}_{6}$ with two azimuthal $\mathrm{H}_{2}$ molecules, d $\mathrm{C}_{60} \mathrm{TiH}_{8}$ with one apical and two azimuthal $\mathrm{H}_{2}$ molecules, and $\mathrm{C}_{60} \mathrm{Ti}_{6} \mathrm{H}_{48}$ structure. (Color figure online) 


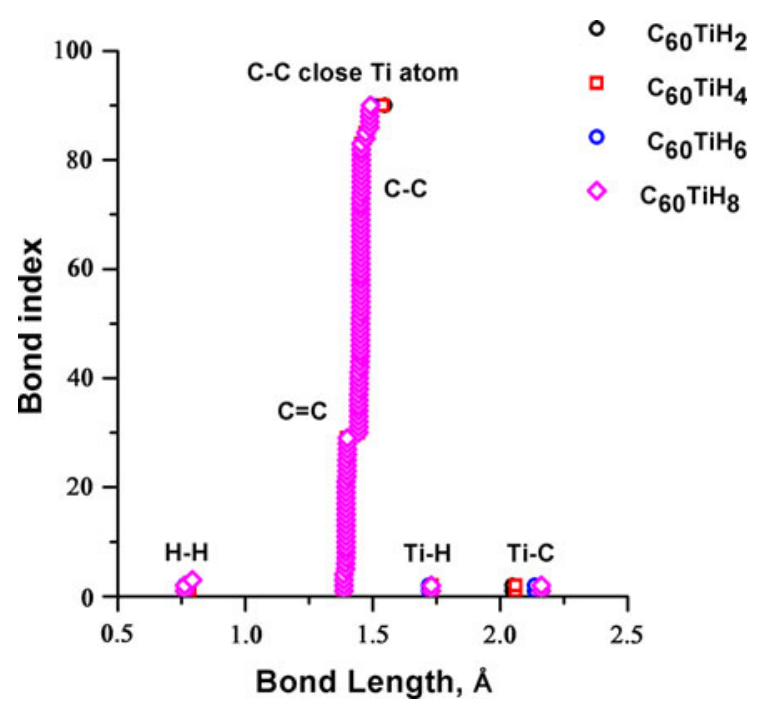

Fig. 2 Bond lengths of the optimized $\mathrm{C}_{60} \mathrm{TiH}_{n}$ compounds. In the case of $\mathrm{C}_{60} \mathrm{TiH}_{8}$ there are two types of $\mathrm{H}-\mathrm{H}$ distances. The $\mathrm{C}-\mathrm{C}$ and $\mathrm{C}=\mathrm{C}$ distances in the $\mathrm{C}_{60}$ framework are between 1.3 and $1.5 \AA$. Other bonds are the $\mathrm{C}-\mathrm{C}$ bonds near and forming the cyclopropane-like bridge, and $\mathrm{Ti}-\mathrm{H}$ and $\mathrm{Ti}-\mathrm{C}$ bonds

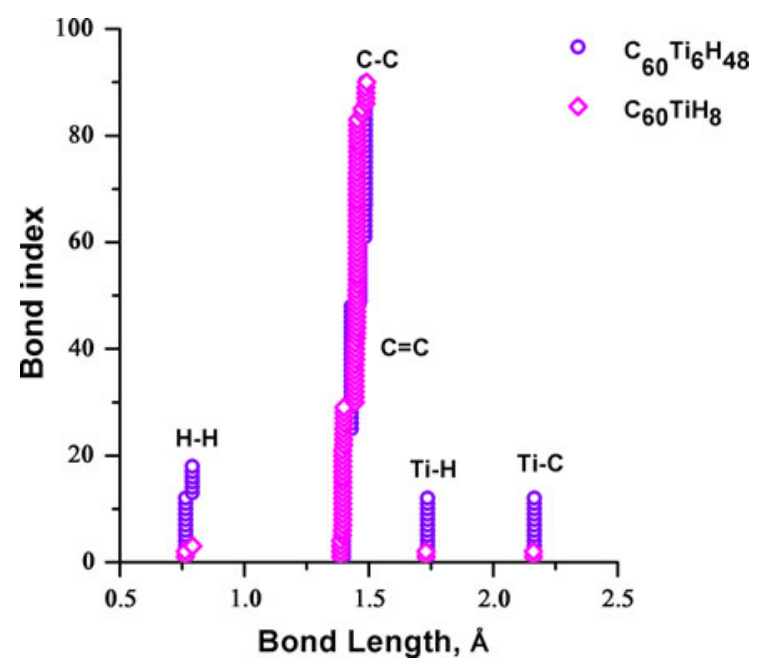

Fig. 3 Bond lengths of the optimized $\mathrm{C}_{60} \mathrm{TiH}_{8}$ and $\mathrm{C}_{60} \mathrm{Ti}_{6} \mathrm{H}_{48}$ compounds. There are two different distances for the $\mathrm{H}-\mathrm{H}$ bond, corresponding to both the azimuthal $\mathrm{H}_{2}$ and the apical $\mathrm{H}_{2}$ bonds, respectively. Other depicted bonds are the $\mathrm{C}-\mathrm{C}$ bonds near and forming the cyclopropane-like bridge, and $\mathrm{Ti}-\mathrm{H}$ and $\mathrm{Ti}-\mathrm{C}$ bonds

have peaks at the same frequencies, whose irreducible representations are $A_{1}, B_{1}$, and $B_{2}$, while the vibrational mode with $\mathrm{A}_{2}$ irreducible representation is only active in Raman spectra. We describe individually the results for the different compounds in the next subsections.
Neutral $\mathrm{C}_{60} \mathrm{TiH}_{2}$ with $\mathrm{C}_{2 v}$ symmetry

The optimized structure (see Fig. 1a) has bond lengths in the range from 1.39 to $2.05 \AA$, and it has 183 normal modes, whose irreducible representations are

$\Gamma=49 \mathrm{~A}_{1}+43 \mathrm{~A}_{2}+45 \mathrm{~B}_{1}+46 \mathrm{~B}_{2}$.

The estimate of $E_{\mathrm{b}}$ for the atomic $\mathrm{H}$ atoms, calculated using a BSSE correction is of $7.82 \mathrm{eV} / 2 \mathrm{H}$, value that implies that the $\mathrm{H}$ atoms are unlikely to desorb.

The maximum in both IR and Raman spectra is at $1715.05 \mathrm{~cm}^{-1}$ (within the $A_{1}$ irreducible representation), corresponding to a $\mathrm{Ti}-\mathrm{H}$ in-phase stretching mode. Near to this peak, at $1693.92 \mathrm{~cm}^{-1}$, the Ti-H out-of-phase stretching mode is also present. From 350 to $700 \mathrm{~cm}^{-1}$ there are three more peaks, attributable to the $\mathrm{C}_{60}$ core vibrations and to the two $\mathrm{H}$ atoms. A mode is located At $364.85 \mathrm{~cm}^{-1}$, corresponding to the wagging mode of the two $\mathrm{H}$ atoms. The scissors mode of the $\mathrm{H}$ atoms is located at $673.14 \mathrm{~cm}^{-1}$.

The Raman spectrum (Fig. 5) has 23 evident peaks, two of them coinciding with the IR active modes mentioned above. In the Raman spectrum we can locate the vibrational modes due to the wagging mode of two $\mathrm{C}$ atoms of the cyclopropane-like ring $\left(963.31 \mathrm{~cm}^{-1}\right)$, the pentagonal pinch of the $\mathrm{C}_{60}$ core, which in the bare $\mathrm{C}_{60}$ molecule is located at $1503.7 \mathrm{~cm}^{-1}$, and the breathing mode at $491.064 \mathrm{~cm}^{-1}\left(496.797 \mathrm{~cm}^{-1}\right.$ for $\mathrm{C}_{60}$ molecule). Moreover, there exist one peak at $1614.62 \mathrm{~cm}^{-1}$ corresponding to the stretching mode of the $(6,6)$ bonds on the $\mathrm{C}_{60}$ core. In order of intensity, the calculated modes in the Raman spectrum are: $\mathrm{Ti}-\mathrm{H}$ in-phase stretching mode, cyclopropane-like ring out-of-phase vibration $\left(1195.26 \mathrm{~cm}^{-1}\right)$, pentagonal pinch mode $\left(1495.13 \mathrm{~cm}^{-1}\right)$, and Ti-H out-of-phase stretching mode. It is worthwhile to remark that the calculation of the Raman spectrum allows us the study of those vibrational modes that are no IR active modes or that are comparatively weak. For example, the pentagonal pinch generates an intense peak on the calculated Raman spectrum.

\section{Neutral $\mathrm{C}_{60} \mathrm{TiH}_{4}$ with $\mathrm{C}_{2 v}$ symmetry}

The optimized $\mathrm{C}_{60} \mathrm{TiH}_{4}$ structure has bond lengths in the range from 0.782 to $2.06 \AA$, and it has 189 normal modes whose irreducible representations are: 


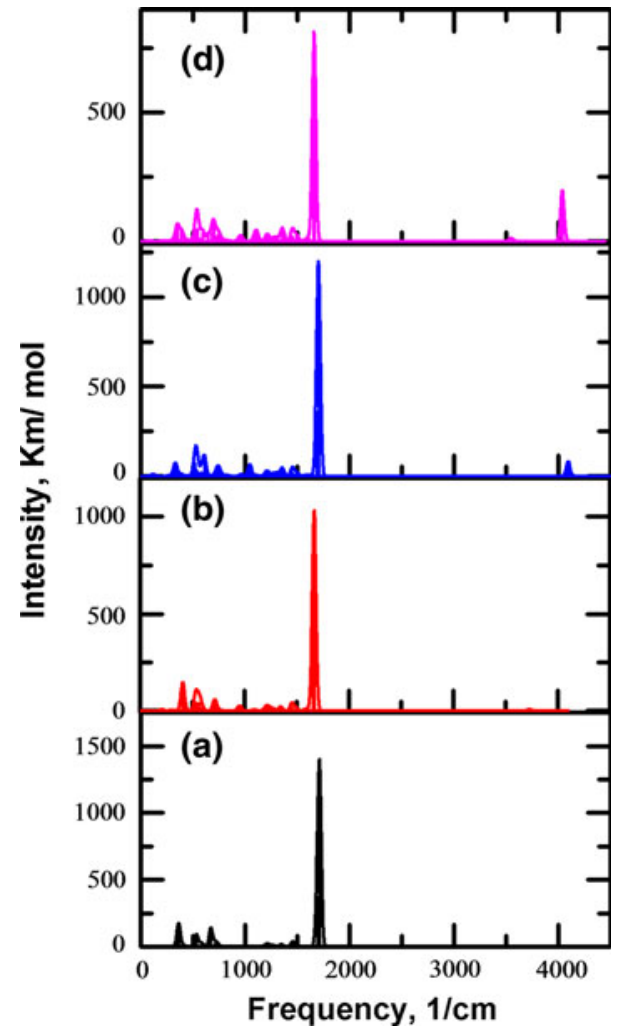

Fig. 4 IR spectra for the $\mathrm{C}_{60} \mathrm{TiH}_{n}$ compounds with $C_{2 v}$ symmetry. a $\mathrm{C}_{60} \mathrm{TiH}_{2}, \mathbf{b} \mathrm{C}_{60} \mathrm{TiH}_{4}, \mathbf{c ~ C}_{60} \mathrm{TiH}_{6}$, and $\mathbf{d ~ \mathrm { C } _ { 6 0 }} \mathrm{TiH}_{8}$

$\Gamma=51 \mathrm{~A}_{1}+44 \mathrm{~A}_{2}+46 \mathrm{~B}_{1}+48 \mathrm{~B}_{2}$.

The apical $\mathrm{H}_{2}$ molecule has an $E_{\mathrm{b}}$ of $0.13 \mathrm{eV}$, as estimated using a BSSE correction.

The IR spectrum shows a maximum around $1672.30 \mathrm{~cm}^{-1}$, due to the $\mathrm{Ti}-\mathrm{H}$ in-phase stretching mode, and the Ti-H out-of-phase stretching mode is located at $1656.87 \mathrm{~cm}^{-1}$. The wagging mode of the two $\mathrm{H}$ atoms bound to the $\mathrm{C}$ atom of the cyclopropanelike ring is located at $409.48 \mathrm{~cm}^{-1}$. The Raman spectrum shows five more representatives peaks, which with the exception the Ti-H vibrational modes, appear as weak signals in the IR spectrum: at $1495.04 \mathrm{~cm}^{-1}$ the pentagonal pinch mode of the $\mathrm{C}_{60}$ core is a maximum; at $3730.38 \mathrm{~cm}^{-1}$ the apical $\mathrm{H}-\mathrm{H}$ stretching mode (weak intensity in IR); at 1656.87 and $1672.30 \mathrm{~cm}^{-1}$ the $\mathrm{Ti}-\mathrm{H}$ vibrational stretching modes-which are active at IR too-, and at $945.792 \mathrm{~cm}^{-1}$, the scissors mode of the $\mathrm{H}$ atoms (weak intensity in IR). At first instance, the presence of one apical $\mathrm{H}_{2}$ molecule into the $\mathrm{C}_{60} \mathrm{TiH}_{4}$ enhances the

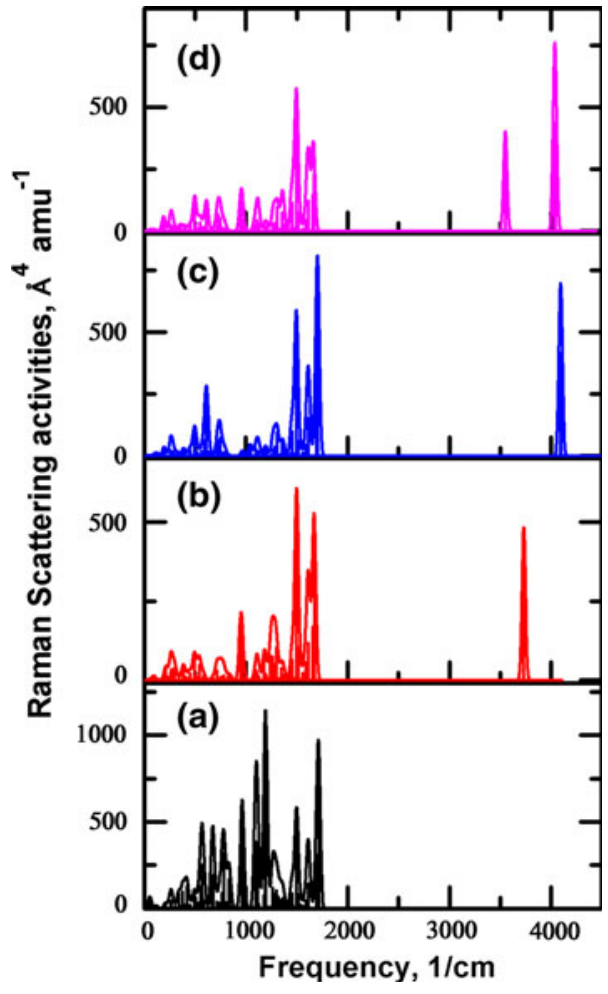

Fig. 5 Raman spectra for the $\mathrm{C}_{60} \mathrm{TiH}_{n}$ compounds with $C_{2 v}$ symmetry. a $\mathrm{C}_{60} \mathrm{TiH}_{2}, \mathbf{b ~ C}_{60} \mathrm{TiH}_{4}, \mathbf{c} \mathrm{C}_{60} \mathrm{TiH}_{6}$, and $\mathbf{d ~} \mathrm{C}_{60} \mathrm{TiH}_{8}$

pentagonal pinch mode of the $\mathrm{C}_{60}$ framework, making it the maximum into the calculated Raman spectrum.

Neutral $\mathrm{C}_{60} \mathrm{TiH}_{6}$ with $\mathrm{C}_{2 v}$ symmetry

Their bond lengths are in the range from 0.761 to $2.135 \AA$ and its 195 normal modes have the irreducible representations

$\Gamma=53 \mathrm{~A}_{1}+45 \mathrm{~A}_{2}+48 \mathrm{~B}_{1}+49 \mathrm{~B}_{2}$.

The two azimuthal $\mathrm{H}_{2}$ molecules are bound with an energy of $0.18 / 2 \mathrm{H}_{2}\left(E_{\mathrm{b}}\right.$ including a BSSE correction).

The IR spectrum has a large peak at $1707.28 \mathrm{~cm}^{-1}$ due to the Ti-H in-phase stretching mode, followed in intensity by one peak at $1691.14 \mathrm{~cm}^{-1}$, likely due to the Ti-H out-of-phase stretching mode, and by a peak at $612.08 \mathrm{~cm}^{-1}$ due to the scissors mode of the two $\mathrm{H}$ atoms with the two $\mathrm{H}_{2}$ molecules moving parallel to the $\mathrm{C}-\mathrm{C}$ bond. Moreover, the spectrum shows weak signals at $4097.60 \mathrm{~cm}^{-1}$ associated to an azimuthal $\mathrm{H}-\mathrm{H}$ inphase vibrational mode with its corresponding out-ofphase mode at $4089.81 \mathrm{~cm}^{-1}$, while the $\mathrm{H}_{2}-\mathrm{Ti}-\mathrm{H}_{2}$ vibrational bending mode is located at $329.72 \mathrm{~cm}^{-1}$. 
The Raman spectrum has its maximum at $1707.28 \mathrm{~cm}^{-1}$, followed in intensity by the pentagonal pinch at $1493.97 \mathrm{~cm}^{-1}$. The third on intensity is the vibration located at $4089.81 \mathrm{~cm}^{-1}$. At fourth place the $4097.60 \mathrm{~cm}^{-1}$ peak is present. In fifth place is the Ti-H out-of-phase stretching mode at $1691.14 \mathrm{~cm}^{-1}$, and finally the $\mathrm{H}-\mathrm{Ti}-\mathrm{H}$ bending mode is at $612.076 \mathrm{~cm}^{-1}$.

\section{Neutral $\mathrm{C}_{60} \mathrm{TiH}_{8}$ with $\mathrm{C}_{2 v}$ symmetry}

All the bonds of the optimized structure lay in the range from 0.764 to $2.161 \AA$, with 201 modes with irreducible representations:

$\Gamma=55 \mathrm{~A}_{1}+46 \mathrm{~A}_{2}+50 \mathrm{~B}_{1}+50 \mathrm{~B}_{2}$.

In the IR spectrum, there are two high-intensity peaks: the first at $1664.92 \mathrm{~cm}^{-1}$ is due to the Ti-H in-phase stretching mode, and the second one at $1655.53 \mathrm{~cm}^{-1}$ that corresponds to the out-of-phase mode. Other weak signals are the azimuthal $\mathrm{H}-\mathrm{H}$ in-phase mode at $4041.15 \mathrm{~cm}^{-1}$, and the out-of-phase is at $4032.46 \mathrm{~cm}^{-1}$. The apical $\mathrm{H}-\mathrm{H}$ in-phase stretching mode is at $3548.71 \mathrm{~cm}^{-1}$, and the scissors vibration of the two $\mathrm{H}_{2}$ molecules is located at $392.908 \mathrm{~cm}^{-1}$.

The Raman spectrum shows a maximum at $1494.01 \mathrm{~cm}^{-1}$ (also observed in the $\mathrm{C}_{60} \mathrm{TiH}_{4}$ compound), which represents the pentagonal pinch. The next in intensity is the $4032.46 \mathrm{~cm}^{-1}$ peak. The peak at $3548.71 \mathrm{~cm}^{-1}$ is on third place, and in fourth place is the mode at $4041.15 \mathrm{~cm}^{-1}$. Other less intense peaks are those due to the $\mathrm{C}-\mathrm{C}$ vibration modes in the $\mathrm{C}_{60}$ core (1,360-1,450 $\mathrm{cm}^{-1}$ range). Moreover, the Ti-apical $\mathrm{H}$ stretching out-of-phase mode is present at $1356.97 \mathrm{~cm}^{-1}$. The scissors mode of the two $\mathrm{H}$ atoms combined with a stretching mode between the Ti atom and the apical $\mathrm{H}_{2}$ molecule is at $950.164 \mathrm{~cm}^{-1}$, and the breathing mode of the $\mathrm{C}_{60}$ core is at $492.2 \mathrm{~cm}^{-1}$. In this compound the order in the strength of the Raman spectrum peaks is similar to the one calculated for the $\mathrm{C}_{60} \mathrm{TiH}_{4}$ compound, where the azimuthal $\mathrm{H}-\mathrm{H}$ modes are absent.

\section{Neutral $\mathrm{C}_{60} \mathrm{Ti}_{6} \mathrm{H}_{48}$ with $\mathrm{T}_{h}$ symmetry}

The $\mathrm{C}_{60} \mathrm{Ti}_{6} \mathrm{H}_{48}$ has 336 normal modes with irreducible representations

$\Gamma=45 T_{u}+45 T_{g}+15 E_{g}+15 A_{g}+7 E_{u}+7 A_{u}$.

The normal modes that are IR actives have a $T_{u}$ irreducible representation, while the Raman-active

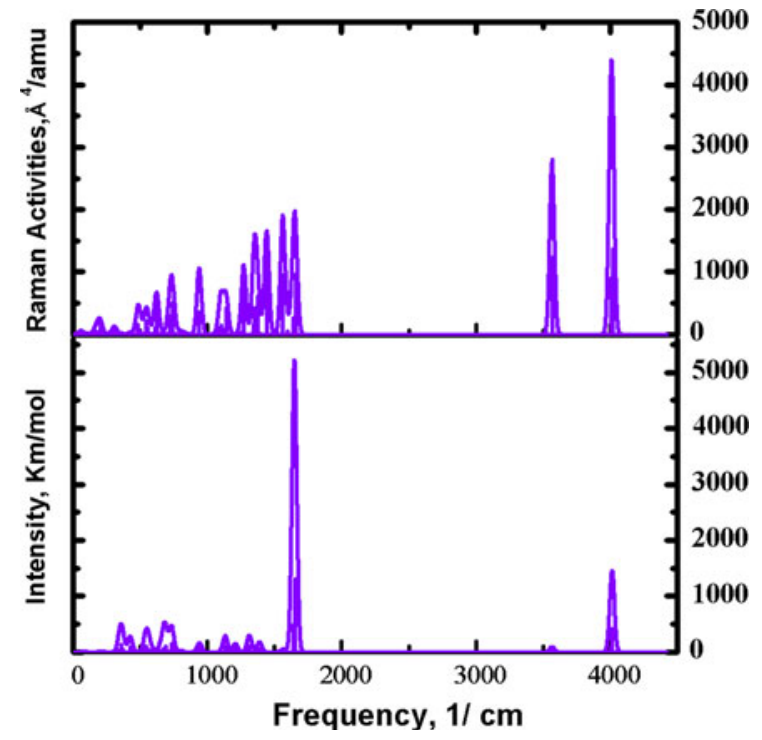

Fig. 6 IR and Raman spectra for the $\mathrm{C}_{60} \mathrm{Ti}_{6} \mathrm{H}_{48}$ structure

modes have $T_{g}, E_{g}, E_{u}, A_{g}$, and $A_{u}$ representations (Fig. 6).

The IR actives modes are threefold degenerated, with the more intense peak in the IR spectrum, located at $1650.18 \mathrm{~cm}^{-1}$, related to three modes of a pair of $\mathrm{H}-\mathrm{Ti}-\mathrm{H}$ bonds located at both sides of the $\mathrm{C}_{60}$ core, vibrating out of phase (Fig. 7a). This vibration mode includes the expansion of two $\mathrm{Ti}-\mathrm{H}$ bonds in one side, and the contraction of two $\mathrm{Ti}-\mathrm{H}$ bonds located in the opposed side of the $\mathrm{C}_{60}$ core. But the Ti-H stretching out-of-phase mode at $1640.45 \mathrm{~cm}^{-1}$, implies the Ti-H contraction and $\mathrm{Ti}-\mathrm{H}$ expansion in one $\mathrm{H}-\mathrm{Ti}-\mathrm{H}$ unit simultaneously (Fig. 7b), which are related with the opposed $\mathrm{H}-\mathrm{Ti}-\mathrm{H}$ unit by a mirror element of symmetry. A triple degenerated peak at $4015.12 \mathrm{~cm}^{-1}$ is related to four azimuthal $\mathrm{H}_{2}$ molecules that are located at both sides of the $\mathrm{C}_{60}$ core. The movement is a contraction of two azimuthal $\mathrm{H}_{2}$ molecules on a side of the $\mathrm{C}_{60}$ core, with an expansion on the opposite side (Fig. 7c).

The peak around $3566.30 \mathrm{~cm}^{-1}$, corresponds to the apical $\mathrm{H}-\mathrm{H}$ stretching mode. Two apical $\mathrm{H}_{2}$ molecules located at both sides of the $\mathrm{C}_{60}$ core participate in this vibration mode, one of them contracting while the other expands itself (Fig. 7d).

The scissors mode at $357.77 \mathrm{~cm}^{-1}$, has two $\mathrm{H}_{2}-\mathrm{Ti}-$ $\mathrm{H}_{2}$ units in both sides of the $\mathrm{C}_{60}$ framework, moving on opposed directions simultaneously (Fig. 7e).

The spectrum has another two less intense modes: at $4004.74 \mathrm{~cm}^{-1}$ the azimuthal $\mathrm{H}_{2}$ out-of-phase 

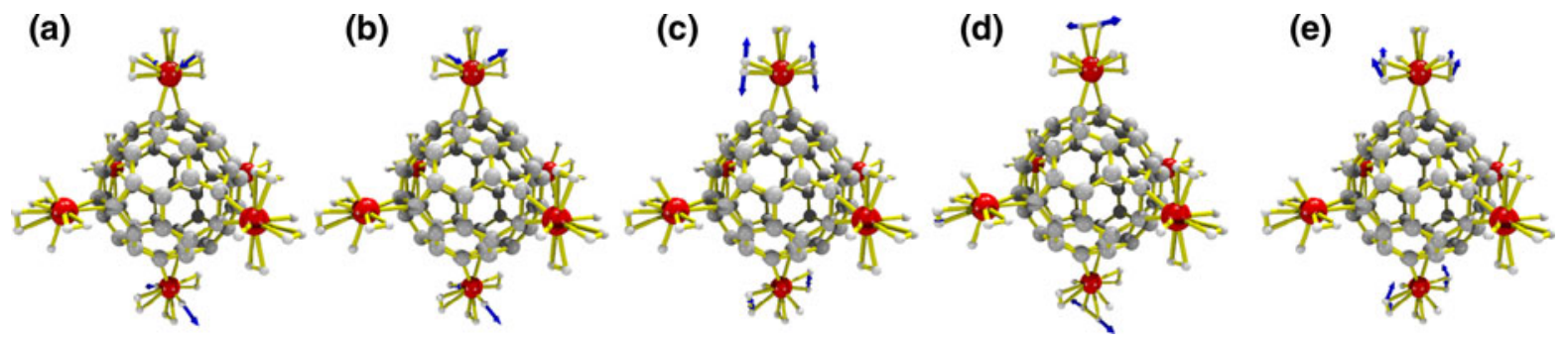

Fig. 7 Five more intense peaks on the infrared spectrum for the $\mathrm{C}_{60} \mathrm{Ti}_{6} \mathrm{H}_{48}$ compound. a $1650.18 \mathrm{~cm}^{-1}, \mathbf{b} 1640.45 \mathrm{~cm}^{-1}$, c $4015.12 \mathrm{~cm}^{-1}$, d $3566.30 \mathrm{~cm}^{-1}$, and e $357.77 \mathrm{~cm}^{-1}$

stretching mode, due to two azimuthal $\mathrm{H}_{2}$ molecules on one side of the $\mathrm{C}_{60}$ core and another two azimuthal $\mathrm{H}_{2}$ molecules on the opposed side, vibrating out-ofphase (the movement between $\mathrm{H}_{2}$ molecules on both sides of the $\mathrm{C}_{60}$ core has a mirror element of symmetry); at $940.997 \mathrm{~cm}^{-1}$ there exist a bending mode, which consists of two $\mathrm{H}-\mathrm{Ti}-\mathrm{H}$ units located on opposed sides of the $\mathrm{C}_{60}$-core vibrating at the same time. All these frequencies correspond only to IR active modes.

On the other hand, the Raman spectrum shows a maximum at $1441.58 \mathrm{~cm}^{-1}$, due to the pentagonal pinch (Fig. 8a). The next peak on intensity is at $4016.23 \mathrm{~cm}^{-1}$ and represents the azimuthal $\mathrm{H}-\mathrm{H}$ inphase stretching mode of all the twelve azimuthal $\mathrm{H}_{2}$ molecules (Fig. 8b), while the out-of-phase mode is present at $4014.88 \mathrm{~cm}^{-1}$, where only two pairs of apical $\mathrm{H}_{2}$ molecules separated by the $\mathrm{C}_{60}$-core participate (Fig. 8c).

There exist a vibration stretching mode of the $\mathrm{C}-\mathrm{C}$ bond of the cyclopropane-like ring at $1271.87 \mathrm{~cm}^{-1}$, that correspond to six $\mathrm{C}-\mathrm{C}$ pairs vibrating at the same time. Other vibration mode is present at $1353.23 \mathrm{~cm}^{-1}$, due to two pairs of cyclopropane-like rings located to the both sides of the $\mathrm{C}_{60}$ core, where each pair expand or contract at the same time. Moreover, the $(6,6)$ bonds near to four cyclopropane-like rings of the $\mathrm{C}_{60}$-core vibrate at $1561.37 \mathrm{~cm}^{-1}$.

At $1657.14 \mathrm{~cm}^{-1}$ there exists a $\mathrm{H}-\mathrm{Ti}-\mathrm{H}$ in-phase stretching mode of all the $12 \mathrm{H}$ atoms bound to the six $\mathrm{Ti}$ atoms. At $4004.71 \mathrm{~cm}^{-1}$ is the out-of-phase azimuthal stretching mode, which includes two pairs of $\mathrm{H}_{2}$ located at both sides of the $\mathrm{C}_{60}$ core. At $3566.3 \mathrm{~cm}^{-1}$ the apical $\mathrm{H}_{2}$ in-phase stretching mode is present, participating two $\mathrm{H}_{2}$ molecules on opposite sides of the $\mathrm{C}_{60}$ framework. The scissor vibration mode of the $\mathrm{H}-\mathrm{Ti}-\mathrm{H}$ bonds is present at $939.67 \mathrm{~cm}^{-1}$, and includes four $\mathrm{Ti}$ atoms and eight $\mathrm{H}$ atoms.

The Ti-H out-of-phase stretching mode is located at $1640.15 \mathrm{~cm}^{-1}$. This mode includes two Ti atoms and four $\mathrm{H}$ atoms, with the $\mathrm{Ti}$ atoms related by a mirror symmetry. The Ti-H in-phase stretching mode is present at $1649.81 \mathrm{~cm}^{-1}$; this vibration includes eight $\mathrm{H}$ atoms bound to four $\mathrm{Ti}$ atoms, where the contraction and expansion occur simultaneously.

The breathing mode of the $\mathrm{C}_{60}$ core is located at $483.78 \mathrm{~cm}^{-1}$; in this mode the six pairs of $\mathrm{C}$ atoms bound to six $\mathrm{Ti}$ atoms stay static, a behavior also observed in the pentagonal pinch.

From all the studied structures, we have found a trend into the enhanced pentagonal pinch mode (Table 2), where the presence of one apical $\mathrm{H}_{2}$
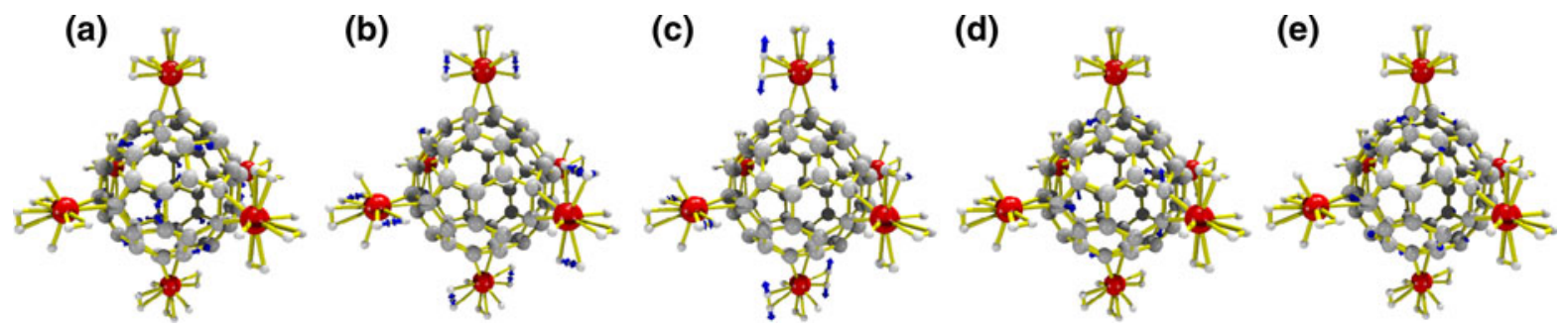

Fig. 8 Five more intense peaks on the Raman spectrum for the $\mathrm{C}_{60} \mathrm{Ti}_{6} \mathrm{H}_{48}$ compound. a Pentagonal pinch at $1441.58 \mathrm{~cm}{ }^{-1}$, b $4016.23 \mathrm{~cm}^{-1}$, c $4014.88 \mathrm{~cm}^{-1}, \mathbf{d} 1271.87 \mathrm{~cm}^{-1}$, and e $1353.23 \mathrm{~cm}^{-1}$ 
Table 2 Bond lengths $(\AA)$, and frequencies $\left(\mathrm{cm}^{-1}\right)$ of selected modes of the calculated $\mathrm{C}_{60} \mathrm{TiH}_{n}$ and $\mathrm{C}_{60} \mathrm{Ti}_{6} \mathrm{H}_{48}$ compounds

\begin{tabular}{lllllll}
\hline Compound & $\begin{array}{l}\text { Ti-H } \\
\text { bond }\end{array}$ & $\begin{array}{l}\text { Ti-H in/ } \\
\text { out-of-phase }\end{array}$ & $\begin{array}{l}\text { Apical } \\
\mathrm{H}_{2} \text { bond }\end{array}$ & $\begin{array}{l}\text { Apical } \mathrm{H}_{2} \\
\text { frequency }\end{array}$ & $\begin{array}{l}\text { Azimuthal } \\
\mathrm{H}_{2} \text { bond }\end{array}$ & $\begin{array}{l}\text { Azimuthal in/ } \\
\text { out-of-phase } \mathrm{H}_{2}\end{array}$ \\
\hline $\mathrm{C}_{60} \mathrm{TiH}_{2}$ & 1.723 & $1715.05 / 1693.92$ & & & & \\
$\mathrm{C}_{60} \mathrm{TiH}_{4}$ & 1.733 & $1672.30 / 1656.87$ & 0.782 & 3730.38 & & \\
$\mathrm{C}_{60} \mathrm{TiH}_{6}$ & 1.720 & $1707.28 / 1691.14$ & & & 0.761 & $4097.60 / 4089.81$ \\
$\mathrm{C}_{60} \mathrm{TiH}_{8}$ & 1.725 & $1664.92 / 1655.53$ & 0.793 & 3548.71 & 0.764 & $4041.15 / 4032.46$ \\
$\mathrm{C}_{60} \mathrm{Ti}_{6} \mathrm{H}_{48}$ & 1.736 & $1650.18 / 1640.47$ & 0.792 & 3566.30 & 0.765 & $4015.12 / 4004.74$ \\
\hline
\end{tabular}

molecule in the $\mathrm{C}_{60} \mathrm{TiH}_{n}$ compounds have the effect of increasing the length of the $\mathrm{Ti}-\mathrm{H}$ bond, shifting its frequency to lower values (see for example the compounds $\mathrm{C}_{60} \mathrm{TiH}_{4}, \mathrm{C}_{60} \mathrm{TiH}_{8}$, and $\mathrm{C}_{60} \mathrm{Ti}_{6} \mathrm{H}_{48}$ ). Furthermore, all the calculated IR and Raman spectra for the $\mathrm{C}_{60} \mathrm{TiH}_{n}$ and $\mathrm{C}_{60} \mathrm{Ti}_{6} \mathrm{H}_{48}$ compounds allowed us to find a correlation of the Raman and the infrared active modes on the $\mathrm{C}_{60}$ molecule and the $\mathrm{C}_{60}$ core of all the studied compounds (Table 3). Also, the shift on the frequency allows us to determinate which modes are more perturbed. For example, three normal modes of the $\mathrm{C}_{60}$ parent, located at $1454.36,1503.07$, and $1460 \mathrm{~cm}^{-1}$, shift by more than $60 \mathrm{~cm}^{-1}$ in the $\mathrm{C}_{60} \mathrm{Ti}_{6} \mathrm{H}_{48}$ compound. This shift shows that the more influenced is the pentagonal pinch with a lower value of about $60 \mathrm{~cm}^{-1}$, while the other frequencies are almost unperturbed: for example the azimuthal $\mathrm{H}_{2}$ frequencies in- or out-of-phase are lower for about

Table 3 Correlation between the calculated IR and Raman-active modes of the bare $\mathrm{C}_{60}$, and their corresponding modes for the $\mathrm{C}_{60} \mathrm{TiH}_{n}$ and $\mathrm{C}_{60} \mathrm{Ti}_{6} \mathrm{H}_{48}$ compounds

\begin{tabular}{|c|c|c|c|c|c|}
\hline $\mathrm{C}_{60}$ & $\mathrm{C}_{60} \mathrm{TiH}_{2}$ & $\mathrm{C}_{60} \mathrm{TiH}_{4}$ & $\mathrm{C}_{60} \mathrm{TiH}_{6}$ & $\mathrm{C}_{60} \mathrm{TiH}_{8}$ & $\mathrm{C}_{60} \mathrm{Ti}_{6} \mathrm{H}_{48}$ \\
\hline \multirow[t]{5}{*}{$265.89\left(H_{g}\right)$} & $258.21\left(\mathrm{~A}_{1}\right)$ & 258.50 & 260.20 & 260.49 & \multirow[t]{5}{*}{$260.50\left(T_{g}\right), 166.95\left(E_{g}\right)$} \\
\hline & $299.27\left(\mathrm{~A}_{1}\right)$ & 298.18 & 288.10 & 287.17 & \\
\hline & $256.87\left(\mathrm{~A}_{2}\right)$ & 257.07 & 259.84 & 260.16 & \\
\hline & $266.53\left(\mathrm{~B}_{1}\right)$ & 266.63 & 266.94 & 267.61 & \\
\hline & $266.98\left(\mathrm{~B}_{2}\right)$ & 267.49 & 264.36 & 264.82 & \\
\hline \multirow[t]{5}{*}{437.42} & 434.08 & 434.08 & 434.01 & 434.08 & \multirow[t]{5}{*}{$429.64,483.00$} \\
\hline & 451.20 & 534.47 & 449.74 & 450.28 & \\
\hline & 433.84 & 433.92 & 434.17 & 434.39 & \\
\hline & 438.24 & 440.52 & 433.78 & 434.11 & \\
\hline & 434.21 & 433.04 & 437.28 & 441.09 & \\
\hline \multirow[t]{5}{*}{720.95} & 718.32 & 720.17 & 719.95 & 719.86 & \multirow[t]{5}{*}{$727.05,724.14$} \\
\hline & 720.31 & 737.51 & 725.46 & 724.58 & \\
\hline & 713.73 & 713.87 & 713.29 & 713.46 & \\
\hline & 720.00 & 719.91 & 722.12 & 722.27 & \\
\hline & 721.77 & 721.95 & 719.64 & 719.60 & \\
\hline \multirow[t]{5}{*}{787.69} & 769.65 & 769.98 & 772.25 & 772.54 & \multirow[t]{5}{*}{$791.03,733.41$} \\
\hline & 785.71 & 785.78 & 785.18 & 785.27 & \\
\hline & 789.00 & 788.72 & 789.62 & 789.59 & \\
\hline & 777.68 & 778.70 & 783.13 & 782.83 & \\
\hline & 780.97 & 779.79 & 780.49 & 782.27 & \\
\hline \multirow[t]{5}{*}{1126.53} & 1125.45 & 1125.67 & 1126.14 & 1216.55 & \multirow[t]{5}{*}{$1221.62,1135.16$} \\
\hline & 1176.64 & 1178.73 & 1198.04 & 1267.56 & \\
\hline & 1113.52 & 1113.20 & 1115.32 & 1115.49 & \\
\hline & 1100.34 & 1102.11 & 1126.48 & 1126.43 & \\
\hline & 1126.09 & 1125.77 & 1101.16 & 1103.60 & \\
\hline
\end{tabular}


Table 3 continued

\begin{tabular}{|c|c|c|c|c|c|}
\hline $\mathrm{C}_{60}$ & $\mathrm{C}_{60} \mathrm{TiH}_{2}$ & $\mathrm{C}_{60} \mathrm{TiH}_{4}$ & $\mathrm{C}_{60} \mathrm{TiH}_{6}$ & $\mathrm{C}_{60} \mathrm{TiH}_{8}$ & $\mathrm{C}_{60} \mathrm{Ti}_{6} \mathrm{H}_{48}$ \\
\hline \multirow[t]{5}{*}{1276.40} & 1260.15 & 1260.50 & 1266.90 & 1267.56 & \multirow[t]{5}{*}{$1267.34,1256.16$} \\
\hline & 1279.72 & 1279.79 & 1281.58 & 1281.67 & \\
\hline & 1265.84 & 1265.88 & 1266.52 & 1266.60 & \\
\hline & 1272.60 & 1272.90 & 1265.05 & 1265.15 & \\
\hline & 1264.58 & 1264.63 & 1272.18 & 1272.44 & \\
\hline \multirow[t]{5}{*}{1454.36} & 1452.87 & 1453.18 & 1454.34 & 1451.85 & \multirow[t]{5}{*}{$1396.41,1353.23$} \\
\hline & 1455.27 & 1455.13 & 1460.96 & 1454.30 & \\
\hline & 1457.07 & 1457.03 & 1456.27 & 1456.31 & \\
\hline & 1457.42 & 1457.33 & 1454.96 & 1455.24 & \\
\hline & 1455.89 & 1455.98 & 1457.23 & 1457.16 & \\
\hline \multirow[t]{5}{*}{1616.89} & 1611.35 & 1611.40 & 1611.31 & 1611.38 & \multirow[t]{5}{*}{$1599.72,1649.80$} \\
\hline & 1614.62 & 1614.83 & 1614.11 & 1614.32 & \\
\hline & 1612.11 & 1612.12 & 1612.43 & 1613.09 & \\
\hline & 1613.96 & 1613.99 & 1613.10 & 1613.06 & \\
\hline & 1613.69 & 1613.62 & 1613.83 & 1614.33 & \\
\hline $496.80\left(\mathrm{~A}_{1}\right)$ & $491.06\left(A_{g}\right)$ & 491.24 & 492.04 & 492.20 & $483.79\left(A_{g}\right)$ \\
\hline 1503.07 & 1495.13 & 1495.04 & 1493.97 & 1494.01 & 1441.58 \\
\hline \multirow[t]{3}{*}{$537.21\left(T_{1 u}\right)$} & $534.71\left(\mathrm{~A}_{1}\right)$ & 534.47 & 534.75 & 534.41 & \multirow[t]{3}{*}{$538.39\left(T_{u}\right)$} \\
\hline & $537.28\left(\mathrm{~B}_{1}\right)$ & 537.11 & 536.12 & 538.92 & \\
\hline & $533.02\left(\mathrm{~B}_{2}\right)$ & 533.06 & 537.03 & 531.47 & \\
\hline \multirow[t]{3}{*}{588.44} & 580.54 & 581.55 & 588.86 & 579.72 & \multirow[t]{3}{*}{581.66} \\
\hline & 581.17 & 581.20 & 589.86 & 590.70 & \\
\hline & 587.41 & 586.96 & 585.21 & 595.68 & \\
\hline \multirow[t]{3}{*}{1213.91} & 1216.74 & 1216.95 & 1216.37 & 1216.55 & \multirow[t]{3}{*}{1215.47} \\
\hline & 1210.29 & 1210.48 & 1213.38 & 1213.20 & \\
\hline & 1212.13 & 1211.65 & 1209.75 & 1209.96 & \\
\hline \multirow[t]{3}{*}{1460.00} & 1460.94 & 1460.69 & 1460.96 & 1460.85 & \multirow[t]{3}{*}{1388.28} \\
\hline & 1457.42 & 1457.33 & 1454.96 & 1455.24 & \\
\hline & 1455.89 & 1455.98 & 1457.23 & 1457.16 & \\
\hline
\end{tabular}

$26 \mathrm{~cm}^{-1}$ in the hexa-coordinated, the Ti-H frequencies are small by around $14 \mathrm{~cm}^{-1}$, but the apical $\mathrm{H}_{2}$ frequencies are around $18 \mathrm{~cm}^{-1}$ larger. The reason for the lower value of the pentagonal pinch in the $\mathrm{C}_{60} \mathrm{Ti}_{6} \mathrm{H}_{48}$ is a weak mode, produced by the holding of $12 \mathrm{C}$ atoms bound to the six Ti atoms.

\section{Summary and conclusions}

In this report we propose the hexa-coordinated $\mathrm{C}_{60} \mathrm{Ti}_{6} \mathrm{H}_{48}$ compound as a viable hydrogen storage material, based on the value of the calculated binding energy of $2.37 \mathrm{eV}$ for the six $\mathrm{Ti}$ atoms bound to the $\mathrm{C}_{60}$ framework. In order to provide some confidence about the studied $\mathrm{C}_{60} \mathrm{TiH}_{n}$ compounds, we have calculated the binding energies for the $\mathrm{Ti}$ atom on the $\mathrm{C}_{60}$, where the $\mathrm{Ti}$ atom is bound to $(6,6),(5,6)$, hexagonal and pentagonal sites. The difference between the more stable $(6,6)$ and the $(5,6)$ site for the $\mathrm{C}_{60}$ Ti structures is $0.58 \mathrm{eV}$, in contrast with a previous calculation by Valencia et al. (2010) that mention that a $0.3 \mathrm{eV}$ value is sufficient to hold one single $\mathrm{Ti}$ atom and to avoid the diffusion and therefore the clustering. It is important to mention here that the difference in energy between the $(6,6)$ and $(5,6)$ sites has to be considered as an indicative energy barrier of possible diffusion path to the $\mathrm{Ti}$ atom, within the quasiharmonic approximation. 
However, the determination of the true diffusion path may be a complex, time consuming task, beyond the scope of this study that focuses on the structural and vibrational properties of these compounds.

We calculate the IR and Raman spectra of the hydrogenated $\mathrm{Ti}$ metal-fullerene compounds, and report the irreducible representation of their normal modes. We have found that a more wide characterization of the studied compounds can be done by the calculation of their Raman spectra. Furthermore, we have found that the presence of an apical $\mathrm{H}_{2}$ molecule enhance the pentagonal pinch of the $\mathrm{C}_{60}$ framework. Since the synthesis of these compounds is feasible, the calculated spectra may play a determining role in the identification of the compounds after the synthesis process, and the approach can be adjusted for the study of other hydrogenated metal-fullerene compounds.

Acknowledgments The authors acknowledge al Departamento de Supercómputo DGSCA-UNAM for the support provided.

\section{References}

Bach AL, Catalano VJ, Lee JW, Olmstead MM, Parkin SR (1991) (.eta.2-C70) $\operatorname{Ir}(\mathrm{CO}) \mathrm{Cl}(\mathrm{PPh} 3) 2$ : the synthesis and structure of an iridium organometallic derivate of a higher fullerene. J Am Chem Soc 113:8953-8955. doi:10.1021/ ja00023a057

Bauschlicher CW Jr, So CR (2002) High coverages of hydrogen on $(10,0),(9,0)$ and $(5,5)$ carbon nanotubes. Nanoletters 2:337-341. doi:10.1021/n1020283o

Durgun E, Ciraci S, Yildirim T (2008) Functionalization of carbon-based nanostructures with light transition-metal atoms for hydrogen storage. Phys Rev B 77:0854051-085405-9. doi:10.1103/PhysRevB.77.085405

Fajan PJ, Calabrese JC, Malone B (1991) A multiply-substituted buckminsterfullerene (C60) with an octahedral array of platinum atoms. J Am Chem Soc 113:9408-9409. doi: 10.1021/ja00024a079

Fajan PJ, Calabrese JC, Malone B (1992) Metal complexes of buckminsterfullerene (C60). Acc Chem Res 25:134-142. doi:10.1021/ar00015a006

Frisch MJ, Trucks GW, Schlegel HB, Scuseria GE, Robb MA, Cheeseman JR et al (2003) Gaussian 03, revision B.03. 2003. Gaussian Inc., Wallingford

Halls MD, Bernhard HS (1999) Comparison study of the prediction of Raman intensities using electronic structure methods. J Chem Phys 111:8819-8824. http://dx.doi.org/ 10.1063/1.480228

Hohenberg P, Kohn W (1964) Inhomogeneous electron gas. Phys Rev 136:B864-B871. doi:10.1103/PhysRev. 136.B864
Iñiguez J, Zhou W, Yildirim T (2007) Vibrational properties of $\mathrm{TiH}_{n}$ complexes adsorbed on carbon nanostructures. Chem Phys Lett 444:140-144. http://dx.doi.org/10.1016/ j.cplett.2007.06.133

Kiran B, Kandalam AK, Jena P (2006) Hydrogen storage and the 18-electron rule. J Chem Phys. 124:224703-224706. http://dx.doi.org/10.1063/1.2202320

Koh W, Choi JI, Lee SG, Lee WR, Jang SS (2011) First-principles study of $\mathrm{Li}$ adsorption in a carbon nanotube-fullerene hybrid system. Carbon 49:286-293. http://dx.doi.org/ 10.1016/j.carbon.2010.09.022

Krasnov PO, Ding F, Singh AK, Yakobson BI (2007) Clustering of Sc on SWNT and reduction of hydrogen uptake: ab initio all-electron calculations. J Phys Chem C 111:1797717980. doi:10.1021/jp077264t

Lee H, Li J, Zhou G, Duan W, Kim G, Ihm J (2008) Roomtemperature dissociative hydrogen chemisorption on boron-doped fullerenes. Phys Rev B 77:235101-1-2351015. doi:10.1103/PhysRevB.77.235101

Mathur P, Mavunkal IJ, Umbarkar SB (1998) Synthetic methodologies and structures of metal- $\left[\mathrm{C}_{60}\right]$ fullerene complexes. J Cluster Sci 9:393-415. doi:10.1023/A:10219 34431858

Shin WH, Yang SH, Goddard WA, Kang JA (2006) Ni-dispersed fullerenes: hydrogen storage and desorption properties. Appl Phys Lett 88:053111-1-053111-3. http://dx. doi.org/10.1063/1.2168775

Sun Q, Wang Q, Jena P, Kawazoe Y (2005) Clustering of Ti on a $\mathrm{C}_{60}$ surface and its effect on hydrogen storage. J Am Chem Soc 127:14582-14583. doi:10.1021/ja0550125

Valencia H, Gil A, Frapper G (2010) Trends in the adsorption of $3 \mathrm{~d}$ transition metal atoms onto graphene and nanotube surfaces: a DFT study and molecular orbital analysis. J Phys Chem C 114:14141-14153. doi:10.1021/jp103445v

Yang XB, Zhang RQ, Ni J (2009) Stable calcium adsorbates on carbon nanostructures: applications for high-capacity hydrogen storage. Phys Rev B 79:075431-1-075431-4. doi:10.1103/PhysRevB.79.075431

Yildirim T, Iñiguez J, Ciraci S (2005) Molecular and dissociative adsorption of multiple hydrogen molecules on transition metal decorated $\mathrm{C}_{60}$. Phys Rev B 72:153403-153406. doi:10.1103/PhysRevB.72.153403

Yoon M, Yang S, Hicke Ch, Wang E, Geohegan D, Zhang Z (2008) Calcium as the superior coating metal in functionalization of carbon fullerenes for high-capacity hydrogen storage. Phys Rev Lett 100:206806-1-206806-4. doi: 10.1103/PhysRevLett.100.206806

Zhang Y, Franklin NW, Chen RJ, Dai HJ (2000) Metal coating on suspended carbon nanotubes and its implication to metal-tube interaction. Chem Phys Lett 331:35-41. http://dx.doi.org/10.1016/S0009-2614(00)01162-3

Zhao YF, Kim YH, Dillon AC, Heben MJ, Zhang SB (2005) Hydrogen storage in novel organometallic buckyballs. Phys Rev Lett 94:155504-1-155504-4. doi:10.1103/Phys RevLett.94.155504

Zope RR, Baruah T, Lau KC, Liu AY, Pederson MR, Dunlap BI (2009) Boron fullerenes: from $B_{80}$ to hole doped boron sheets. Phys Rev B 79:161403-161404. doi:10.1103/Phys RevB.79.161403 